\title{
Shifting Meanings, Forgotten Meanings: Metaphor as a Force For Language Change
}

(Mudanças de Significados, Significados Perdidos: A Metáfora como uma Força na Evolução das Línguas)

Kelly HoLmQuist

(English and Philosophy, Idaho State University)

\begin{abstract}
All living languages are in a constant state of evolution. Metaphorical usage is an important driving factor in that process of evolution; the blending of concepts within metaphor leads to the diversification of the reference of words used metaphorically. It can occur that a metaphorical usage becomes conventionalized. This, in turn, leads to shifts in the meanings of those words. Metaphorical usage can occur in a variety of forms, including metonymy, synecdoche, and euphemism. The effects of metaphorical usage-and the closely related figure, simile-can even be seen in the evolution of the grammatical structures of many languages. I present various examples which demonstrate the role of metaphorical usage in the evolution of word-meanings and grammatical structures from PIE to modern Indo-European languages.
\end{abstract}

KEY-WORDS: language evolution, changes in meaning, metaphorical process.

RESUMO: Todas as línguas vivas estão em constante evolução. O processo metafórico tem um papel importante nessa evolução; a fusão de conceitos em uma metáfora leva à diversificação da referência de palavras usadas metaforicamente. Um uso metafórico de uma palavra pode tornar-se convencional, o que pode, por sua vez, levar a mudanças nos significados dessa palavra. O uso metafórico pode ocorrer de várias formas, incluindo metonímia, sinédoque e eufemismo. Os efeitos do uso metafórico - e da figura estreitamente a ele relacionada, o símile- podem ser percebidos até mesmo na evolução de estruturas gramaticais de muitas línguas. Eu apresento vários exemplos que evidenciam o papel do uso metafórico na evolução dos significados das palavras e estruturas gramaticais desde o Proto-indoeuropeu até línguas modernas indo-européias.

PALAVRAS CHAVEs: evolução das línguas; mudança de significado; processo metafórico.

D.E.L.T.A., 22:EsPECIAL, 2006 (95-107) 


\section{Introduction}

In this paper, I will look first at the nature of metaphors and what the metaphorical use of words and ideas allows us to do with language. I will then look at how this human tendency to assign metaphorical meanings to words (and phrases) can lead to the loss of the original meanings of those words (and phrases) over time. I will examine three ways in which words shift meaning: the first is metaphorical shifting, the substitution of a new metaphorically derived meaning of a word for its traditional meaning; the second is the substitution of a descriptive label - either as a euphemism or as simile - for an older term; and the third is the synthesis of new terms either to replace old terms or to convey new ideas. This study is based on the reconstructed lexicon of the Proto-Indoeuropean language; most words in modern European, Persian and Hindu languages are descendent from these roots. The Proto-Indoeuropean language has had to be reconstructed because it was a pre-literate language whose speakers left no written records. Admittedly, there is some debate over the original forms of some of the reconstructed roots, but for the purpose of this paper, I will assume that the work of recent philologists has given us a fairly accurate representation of this lost language, and of the original meanings of these roots.

\section{Simile, Metaphor, Metonymy, and Synecdoche}

Although my focus in this paper will be the manner in which the human capacity for metaphorical thought and expression promotes language change over time, I will also consider the related phenomenon of simile. For the purpose of this paper, I will define a simile as an overt comparison of one thing to another in order to elucidate some essential quality that it has. In English, words which are coined as similes are usually adjectives. There are several suffixes which are used to form simile-adjectives: the suffix "-like" ("Polyester often has a silk-like texture"); "-ish," from which is derived terms like "outlandish" (i.e., "like something from the outland"). This group also includes some adjectival suffixes which are less overt in the comparisons they invoke, including "-esque," "-an," and "ine"; these are used to suggest an association between the object being described and a specific "other" (e.g., "Tolstoy-esque," "Jacksonian," or "Mozartine"). 
It is sometimes argued that metaphors are really just elliptical similes, or in other words, metaphors are really only descriptions of the similarities between two objects in which the speaker leaves out some of the words which demonstrate the metaphor to be a comparison. But we should be careful here: a simile is a comparison in which one object is explicitly likened to another, as in " $X$ is like $Y$." The essential difference between metaphor and simile is that in a simile construction, the idea of a distinction between the tenor and the vehicle is overtly signaled. The mapping of the source domain onto the target domain is limited in advance by the comparative structure of the simile; implicit to this comparison is the acknowledgment of a distinction between $X$ and $Y$. That is to say, there is some way in which $X$ is like $Y$, but $X$ is not identical to $Y$. A simile invites the question, "In what respect is $X$ like $Y$ ?" but implicitly suggests a limitation on the mapping of the qualities of $Y$ onto $X$ : " $X$ is like $Y$ in this way ..." Because simile entails the additional step of acknowledging the distinction between the target domain and the source domain, it is cognitively more complex than metaphor. But this explicitness also makes simile (arguably) less interesting than metaphor: Metaphor does not express likeness per se, because it does not acknowledge a distinction between $X$ and $Y$. Where simile imposes a limitation on the mapping of the source domain onto the target domain with its implicit distinction between source and target, metaphor invites an open ended mapping of the source domain onto the target domain.

Consider the following simile and its corresponding metaphor. Suppose I say, "Jon is like a bear before he has had his St. John's Wort." In the mind of the listener, a list of bear-like attributes unfolds, but since Jon is not identical with a bear, the listener must choose among those attributes to find the most appropriate ones to apply in order to describe Jon before he takes his herbs. Now suppose that I say, "Jon is a bear before he has had his St. John's Wort." The same list of bear-like attributes still unfolds in the listener's mind, but since I haven't used the restrictive comparative structure of simile, the listener is invited to apply the entire list of ursine qualities to Jon as an open-ended (unrestricted) description. The use of metaphor gives that description a sense almost of conferring "bear-hood" on Jon because he shares an essence with the bear, i.e., the undefined qualities which describes both. This is to be distinguished from the simile, which only establishes that Jon has some qualities which are bear-like. 
In summary, simile is cognitively more complex than metaphor; the extra step of recognizing the distinction of Jon and the bear places the onus on the listener of selecting among the pertinent shared qualities shared between the two to make sense of the statement "Jon is like a bear". Metaphor, on the other hand, elucidates an object by conferring (or mapping) the qualities of another object onto it as a concrete description of it. Rather than making a comparison between one object and another, a metaphor "transfers" (literally a "carries across"; metaphor is formed from the Greek cognates of the same roots) the description of one object to another non-identical object by way of a verbal construction which intentionally redirects that description by redirecting the audience's attention from the literal meaning of the statement to a meaning other than the literal meaning.

But the power of metaphor does not only lie in its potential to map a new set of descriptive qualities of one object onto another; metonymic metaphors limit or shift the scope of the set of descriptors it invokes for its referent. I would like to further refine my discussion of metonymy by considering synecdoche, a special class of metonymy. Linguists generally do not make a distinction between metonymy and synecdoche; the concepts of the part for the whole and the whole for the part seem to have been subsumed by the concept of metonymy, the use of a term for a closely related phenomenon to refer to another phenomenon. This is problematic because a metonym is clearly a metaphor in that the tenor is distinct from the vehicle. An example of this is the sentence "Chicago lost the seventh game of the playoffs." The subject of the sentence is obviously not the city of Chicago, but rather the professional baseball team which operates out of Chicago. The two entities are closely associated, but they are not identical, and do not necessarily even share a part-to-whole relationship (the members of the team do not necessarily all live in Chicago). The metonym focuses the mapping of the source onto the target by conveying the magnitude of the impact of this event; the loss of the game was a disappointment not only to the members of the team itself, but also to the people who live in the city with which the team is associated.

In synecdoche, the term for a part is used to refer to the whole. This limits and focuses the reference because the source domain is usually less rich in meaning than the target domain. Consider the following figure: "All hands appeared on the deck." In this case of synecdoche, the literal 
statement can be shown to be true; that is to say, all of the hands appeared on the deck when all of the sailors appeared on the deck. But the term "hands" is nevertheless metaphorical; it is not literally the hands of the sailors, but rather the sailors themselves to which it refers. The effect of this synecdochal reference is to focus on and magnify specific capacities in which the sailors serve. They are on the deck to perform the activities that they perform with their hands (work activities), rather than other activities which might be associated with sailors (e.g., to tell stories, to sing, to drink). To refer to them with the term "hands" rather than the explicit label "men" is to define, limit, and magnify their role in relation to the speaker.

\section{Metaphor and the Evolution of Word-Meanings}

The tendency to think and speak in metaphors can be seen almost universally wherever and whenever language is used. The previous sentence is an example: we don't literally see language; we usually hear it. Even when we do see language in written form, we don't "see" abstract phenomena like tendencies and metaphors; we intuit them. As that sentence was being written, the author was not consciously aware that he was using the word "see" metaphorically. It is common for metaphorical uses of words and phrases to become so ingrained in conventional speech that the original metaphorical derivation of their meaning is either ignored or completely forgotten. Metaphors whose literal meanings are forgotten are "dead metaphors."

It is in this process of metaphorical extension and the subsequent death of those metaphors which contributes to the constant transformation of language over time. But to understand how metaphor death contributes to language change demands a working definition of "meaning." For any word, a "central" referent can be identified, as well as any number of other "peripheral" referents. Peripheral referents tend to accumulate to the word over time as its meaning is extended through metaphorical usage. According to Turner and Fauconnier (1999), when a word is used metaphorically, the source domain and the target domain are blended in the metaphor, and often new ideas arise within the resultant blend which cannot be found in either the source domain or the target domain. They offer the example of the "bullish" traders on Wall Street who, during a slump in the market, 
"[had] their horns pulled in" (p. 404). In the blended metaphor, the normally aggressive traders have metaphorical horns which they can retract when the market is not favorable, an ability that real bulls do not have. For the present discussion of metaphor, it is important to understand that the resulting conceptual mix enriches the metaphor, which, in turn, enriches the referential scope of the source term if that metaphorical usage becomes conventional. The metaphorical uses of a given term can become quite diverse, and this can lead to a remarkable variety of reflexes. This diversification of the reference of a given word can lead to the evolution of its meaning and the rise of new words from it; as a peripheral meaning of a given word becomes more widely used, it may eventually replace the original central meaning of the word, or it may assume a divergent pronunciation and become a distinct word. When this occurs, the word has made a metaphorical shift in meaning. Ultimately, the original central meaning may be entirely forgotten. An example of this is the word "engine," which comes from the Middle English ingen, meaning "inborn talent"; originally, the modern meaning of the word arose as a metaphorical reference to the things created by people with such talent. As that meaning has come into general usage, the original meaning of the word has been lost.

This is not to say that all metaphorical extension of a word will necessarily lead to the loss of the original meaning of that word; our language has many frozen metaphors which can easily be traced back to the original literal meanings. But those meanings are generally not conscious to the speaker who uses those terms. The derivation of terms for technological innovations, for instance, can often be deduced easily, although the use of those terms invokes little association with the objects to which those terms originally referred. For example, we refer to the "face" and "hands" of a clock without feeling that we have personified the clock, although those terms were originally derived metaphorically from the personification of the clock.

I am not referring here to a simple shift in the part of speech of a given word; for example, the noun "course" comes into English from the French cours, which in turn comes from the Latin noun cursus, which means both "course" and the action which is done on the course, "run." Cursus is the past-participle form of currere, which means "to run." The meaning of the noun cursus is logically-and grammatically-derived from the verb. Although the phonology of the word has changed from its Latin form, the word 
"course" is still the same thing that it was in Latin, "that which is run." This same type of semantic shift can be seen in the word "god," which comes from the Indo-European root *ghau, which means "to invoke"; even today the god is the one invoked (Watkins, 2000, p. 31). Metaphorical shifting, by contrast, really amounts to a shifting of meaning from the original root to the new meanings of the reflexes.

Many words begin as metaphorically descriptive phrases which later collapse into single words. For example, the word "window" originally comes from the metaphorical description of that object as the "wind eye," although we no longer recognize the description as metaphorical, and, in fact, "eye" is not even recognizable anymore as a part of the word (Neufeldt, 1991, p. 1530). This collapsing of phrases is also exemplified by the word "alarm." This word comes from the French alarme, which comes in turn from the Italian all'arme, a phrase meaning "to arms" (Neufeldt, 1991, p. 30) The Italian phrase represents a metaphorical shift; originally the phrase must have been something along the lines of, "Sound the [call] to arms (all'arme)." The phrase became metaphorical because of the omission of the noun "call"; the phrase "to arms," which describes the noun "call" in the original phrase, stands in metonymically for that noun. This is a subtle shift from description to metonymy, but it demonstrates how metaphors can increase in their "metaphorical" quality as they come into wider usage. The term "alarm" was originally a simple substitution of a descriptive prepositional phrase for the noun it described ("call"), but as the phrase collapsed into a single word, it also made a semantic shift, becoming a verb. Thus, "to alarm" someone is not to call them to arms; rather, it is to place them in a state of apprehension, the kind of state which might - in the original usage of the term - have caused someone to feel a need to arm himself. The semantic shift from the original noun form has increased the difference of meaning between the original non-metaphorical sense of the phrase "to arms" and the current usage of the word "alarm."

\section{Metaphor, Simile, and the Evolution of Grammatical Structures}

A related phenomenon is the collapse of words and phrases into affixes. The Spanish adverbial suffix -mente is an example. In Latin, the language from which Spanish is descendent, there is a complex set of adverbial 
inflections denoting three types of adverbs, simple adverbs, comparative adverbs, and superlative adverbs (Ashley and Lashbrook, 1988, p. 281). But as the inflectional system was simplified in the Vulgar Latin language which eventually evolved into Spanish, this elaborate adverbial system fell out of use. It was replaced by the metaphorical phrase "in mind," the blank filled with the ablative case of whatever adjective describes the way in which an action is done. Thus, the word "alone" (i.e., "I walked alone"), which in the original Latin is solius becomes "in lone mind," or sol mente, or in modern Spanish, solamente. Most Spanish adverbs which use the -mente suffix can be demonstrated to be a composite of the Latin feminine ablative form of the adjective and -mente, the ablative case of mens ("mind"). A remarkably similar pattern can be seen in the English adverbial suffix "ly." Old English originally had an adverbial suffix which can be seen in the adverb lange ("long," as in "We waited long"), which is derivative of the adjective lang ("long," as in "a long time") (Sweet, 1990, pp. 42-43). But the adverbial declensions were not easily distinguishable from several of the adjectival declensions. For this reason, a new, clearly adverbial suffix was adopted, the adverb -lice, which meant "-like." There was also a corresponding adjectival suffix: -lic. Thus an adjective with an ambiguous ending such as bl\$pe ("glad, merry") could be transformed into a clearly discernable adverb, bl\$pel§ce ("gladly"). As Old English became Modern English, both suffixes were simplified into the modern "-ly" suffix, which either converts a noun into an adjective, or converts an adjective into an adverb. The difference between the phenomena that we see in the Spanish -mente and the English "-ly" is that where the former suffix is derived from a metaphorical construction, the latter is derived from a simile ("gladly" literally means "glad-like"). It is, in effect, the fossilized form of a dead simile.

\section{Description, Euphemism, and the Naming of New Discoveries}

Both metaphorical shifting of words and the reduction of metaphors and similes to suffixes are examples of one pattern of language change: the reduction of semantic meaning at the phrase-level to simple morphological meaning. Both -mente and "-ly" began as elements from which phrases were constructed, but when the syntactical constructions of those phrases 
were no longer understood, they became simple morphemes; though they still allowed the speaker to express essentially the same ideas in combination with adjectives, their effect in the ear of the listener was no longer the same. When these words and the phrases they serve to construct become simple morphemes, they lose some of their descriptive power. This is a phenomenon which can be seen in the literature of many cultures. Scholars of ancient literature have discussed the descriptive quality of the language of cultures at the beginning of their literate period. The term used by these scholars is "divine-concreteness." Familiar examples from Homer's poetry are labels like '“fleet-footed Achilles,' 'bolt-hurling Zeus,' [and] "the wine-dark sea." (Abrams, 1999, 82). Such epithets are evidence of the oral culture in which they were created; the Iliad and the Odyssey were composed at the beginning of Greek literacy and transmitted orally for some time before they were written down. These recurrent epithets made the poems easier to memorize; but they also suggest the descriptive quality inherent in the pre-literate language of the Greek culture. The same type of descriptive labels can be seen in Old English, where they are referred to as "kennings": "the whale road" is used to refer to the sea, the metonymic term "the ring-giver" is used to refer to a king, and "the ringed-prow" is used to refer to a ship (Abrams, 1999, p. 99).

My purpose in drawing attention to these descriptions is to demonstrate the types of descriptive labels which are often collapsed into simple words whose derivation is ultimately forgotten. The word "pajamas" is an example: this word comes to the Hindi language from Persian, where it occurs as a combination of the words $p \sim i$ ("leg") and $j \sim m a$ ("garment") (Neufeldt, 1991, p. 971). By the time it is borrowed into English, it has lost the descriptive flavor of the original combination of terms; it is only a single word, a simple morpheme (arguably two, if we count the "-s" as a plural marker).

Euphemisms present another interesting case; a euphemism is a term used to allow the speaker to avoid using another term which he may feel compelled to avoid. Euphemisms are metonymic descriptive phrases. An example is the term "bathroom"; this is a description which refers explicitly to one activity which occurs sometimes in that room. Referring to this relatively inoffensive activity helps the speaker to avoid referring to the type of activity which occurs in this room much more frequently than bathing, i.e. urination and defecation; nobody would want to have to say, 
"I'm going to the defecation-room." There are various reasons that a speaker might choose to express himself in euphemisms. A euphemism might be used to help a speaker avoid directly using a disparaging label. The term "hussy" is an example: this term comes from the Middle English buswife, "housewife" (Neufeldt, 1991, p. 660) and was used to dismiss a woman as ignorant, although by extension of its meaning through metaphorical usage, it eventually came to mean a woman of questionable morality. Euphemisms can also help a speaker to avoid directly referring to something which is considered distasteful within his or her culture, e.g., "bathroom," cited above.

Euphemisms can also help a speaker to avoid naming something which he or she might fear for some reason. For instance, there is an Indo-European root for "bear," *rtko-, which has reflexes in the Latin ursa; in the Germanic languages there is a parallel unrelated term for "bear," *berÇ, which arises from the descriptive phrase "the brown animal," a synecdochal reference to the animal these speakers feared. Watkins refers to this phenomenon as "taboo replacement" (2000, p.72). In many cultures, to name something is to invoke it. It is easy to imagine that people living in the forests and mountains of Central and Northern Europe would be much more likely to encounter bears than would be the people of the Mediterranean region; therefore, they would be much more likely to fear an encounter with a bear, and they would be more likely to refer to the bear with a euphemistic term like "the brown animal." Thus we find a reflex of the original IndoEuropean word for bear in Latin, but we don't find that word among the Germanic people. The euphemistic term *berÇ has supplanted the original Indo-European term, although reflexes of that original root have returned to English by way of the Latin ursa, which gives us the word "ursine". A similar substitution occurs in Slavic languages with the word $<, * \mathcal{E}$,*। (myédved), a term which comes from the euphemism "honey-eater." Often the euphemism becomes the standard way of referring to the object which its original users were afraid to name directly, and the original words for those objects are forgotten.

Metaphorical shifting can also occur when new objects enter into a culture and terminology must be coined to refer to them. An example of this phenomenon is the word "pearl." Speakers of the original IndoEuropean language did not live by the ocean; therefore they had no opportunity to encounter pearls. But as they began to spread geographically, some groups of Indo-European language speakers did encounter these 
objects, and they had to come up with a way to refer to them; they chose (probably for several reasons) to use a derivative of the word *persna-, which meant "heel" (Watkins, 2000, p. 67). Although these new objects were clearly not heels, the term seemed to these people to be an adequate label for this new object. It is a common tendency among language speakers to describe new (or newly encountered) things in terms of what those things resemble in one way or another. A similar phenomenon can be seen in modern English: all of the paraphernalia associated with personal computers has been created and labeled within the last thirty years. The creators of these objects had to come up with labels to refer to them. Thus, we have an object such as a "mouse" which allows us to use a personal computer, but this object is clearly not a real mouse; the label has only been assigned because of some supposed resemblance it has to the animal mouse. This pattern of referring to new inventions with familiar terminology can also be seen in the terms "face" and "hand" cited above, referring to the parts of a clock. Our ability to think metaphorically allows us find (seemingly) appropriate labels for the new things that we find or invent.

\section{Some Further Examples}

The results of metaphorical shifting can be observed in the modern reflexes of most Indo-European roots; I will consider three representative examples of metaphorical shifting from the meanings of Indo-european roots to the meanings of their reflexes. The first root I will examine is *ar-, "to fit together." By way of metaphorical extension, it has become the noun "arm" in English (that which is used to fit things together). As a description in Greek *ar- has become aristos ("the most fitting; noble," or literally, "those who are put-together the best"); this, in turn, has led to the word "aristocracy". Through a semantic shift, it has become the word ars in Latin, ("art"), meaning "that which is fit together." Finally, the modern reflex represented by the Spanish verb armar ("to assemble") has retained much the same meaning as the original root, but this is now a more peripheral meaning of the word.(Watkins, 2000, p. 5).

The next root I will look at is $*_{s k e i-}$, "to cut, to split." This root represents an example of the diversity of reflexes which can arise from Turner and Fauconnier's conceptual integration and the metaphorical extension which results from it. In Latin, this root makes a metaphorical 
shift to become scire, "to know" (literally, "to separate one thing from another") In Old English *skei- becomes scinu, "the piece cut off" (a description), a reflex which retains the original meaning of the word. But

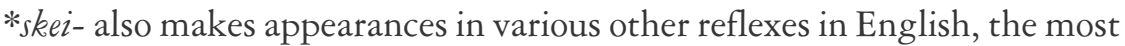
notable of which is "shit." This word comes to us by way of the protoGermanic *skitan, a word which means "to defecate, to separate," a clearly euphemistic usage (Watkins, 2000, p.77). This variety of reflexes for $*_{s k e i-}$ suggests that the concepts of "to cut, to split" may have been a particularly productive source domain during the preliterate periods of some IE languages.

Finally, I will look at the two occurrences of "ear" in English: the one with which you hear and the kind that grows on corn-stalks. At first glance, the latter "ear" appears to be a metaphorical extension of the former "ear." But they can be traced back to completely different roots. The "ear" through which one hears is a reflex of the Indo-European root *ous-, "ear" (Watkins, 2000 , p. 61), whereas the "ear" of corn comes by way of the proto-Germanic *abuz- "a spike, an ear of grain"; this comes from the Indo-European *ak, "sharp." It is possible that when the two terms came to resemble each other enough, speakers began to make a metaphorical association between the two, and subsequently began to treat them as homophones. If this is the case, it demonstrates that the capacity to use words metaphorically can lead not only to the formation of new words; it can also lead to the merging of words into a single form with a richer set of meanings.

\section{Conclusions}

In this paper, I have looked at the ways in which the human capacity to think and speak metaphorically causes languages to be in constant flux. For historical linguists, the close and careful study of modern languages can often reveal a great deal about the cultural history of those languages. The evidence of metaphor-driven language change can still be seen in IndoEuropean languages today, even though many of those changes occurred before recorded history. From this evidence, it may be possible to learn more about the cultures, attitudes, and world-views of the people who spoke these languages before they were recorded. Possible areas of future research include analysis of the cognitive metaphors which can be extrapolated from the reconstructed Proto-Indoeuropean language, a more 
extensive study of euphemisms and the cultural values they suggest, further examination of conceptual integration within PIE roots as can be demonstrated in the range of their reflexes, further research into the factors which lead to homophony among reflexes of widely different roots, further research into the general causes of the substitution of metaphorical terms for explicit terms, and research into the ongoing processes language evolution and the role of figurative usage in that process.

E-mail: holmkell@isu.edu

\section{REFERENCES}

Abrams, M. H. 1999. A Glossary of Literary Terms ( $7^{\text {th }}$ ed.). Fort Worth, Texas: Harcourt Brace College Publishers.

Ashley, Clara W. and Austin M. Lashbrook. 1988. Living Latin. Lincolnwood, Illinois: National Textbook Company.

Neufeldt, Victoria (Ed.). 1991. Webster's New World Dictionary. New York: Prentice Hall.

Sweet, Henry. 1990. Sweet's Anglo-Saxon Primer. Oxford: The Clarendon Press.

Turner, Mark and Gilles Fauconnier. 1999. A Mechanism of Creativity. Poetics Today, 20 (3), 397-418.

W ATKINs, Calvert. 2000. The American Heritage Dictionary of Indo-European Roots. Boston: Houghton Mifflin Company. 